\title{
Hip arthroscopy: the new frontier of hip surgery
}

\author{
Alessio Giai Via \\ Corresponding author: \\ Alessio Giai Via, M.D. Department of Orthopaedic \\ Surgery, Adult Reconstruction Surgery Hip/Knee and \\ Hip Arthroscopy, \\ La Fontecilla 441, Las Condes, \\ Santiago de Chile, Chile \\ tel: +393396298768 \\ E-mail: alessiogiaivia@hotmail.it
}

A painful hip in young adults is a common pathology in modern sport traumatology. The prevalence of groin pain in young and active patients is high, and femoroacetabular impingement the most common pathology in athletes with groin pain. Hip arthroscopy has greatly evolving in the last few years, and, since femoroacetabular impingement was described by Prof. Ganz in 2003, great advances in understanding the biomechanics of the hip have been made. Many intra- and extra-articular pathologies are suitable for hip arthroscopy, and have been treated with promising results. However, despite the great advances in arthroscopic procedures to date, some hip pathologies remain still under-diagnosed, and some indications are still controversial. Therefore, as many or- thopaedic surgeons are now approaching the fascinating world of hip arthroscopy, some clarity on this topic is due. Many well known hip surgeons and world experts participated in this issue of Muscles, Ligaments and Tendons Journal. The topic of hip arthroscopy has been approached systematically, starting from anatomy, imaging evaluation, and current indications. Furthermore, new concepts are described to help hip surgeons and arthroscopists to have better insight of the complicated world of groin pathology.

The idea to publish an issue about hip arthroscopy was suggested by Dr. Francesco Oliva, while I (A.G.V.) was attending my hip arthroscopy fellowship (I.S.H.A. - International Society for Hip Arthroscopy Fellowship) at the Department of reconstructive surgery of the hip, directed by Dr. Rodrigo Mardones in Santiago de Chile. It was a superb experience which allowed me to improve my knowledge on the pathologies of the young adult hip, although I would have wished to be more involved in surgical practice, the essential purpose of all young surgeons. I wish to thank Prof. Nicola Maffulli and Dr. Francesco Oliva, my mentors. Many thanks to the ISHA family to have given me the opportunity to join their world, and to Dr. Rodrigo Mardones for all his teachings. Finally, special thanks to my family, my mother, my father and my grandmother, who always supported me during my studies and travels. 